\title{
Investigations of geopolymeric mixtures based on phosphate washing waste
}

\author{
R.Dabbebi ${ }^{\mathrm{a}, \mathrm{b}}$, S.Baklouti ${ }^{\mathrm{a}}$, J.L. Barroso de Aguiar $^{\mathrm{b}}$, F.Pacheco-Torgal ${ }^{\mathrm{b}}$, B.Samet $^{\mathrm{a}}$ \\ ${ }^{a}$ University of Sfax, Laboratory of Industrial Chemistry, Sfax 3038, Tunisia \\ ${ }^{b}$ University of Minho, C-TAC Research Centre, Guimarães, 4800-058, Portugal
}

\begin{abstract}
The extraction of the phosphate ore produces a high amount of waste causing serious environmental problems. This waste, termed as phosphate washing waste, was filtered and dried at $105^{\circ} \mathrm{C}$ for $24 \mathrm{~h}$ to remove the water. The dried waste was milled and then sieved in a $100 \mu \mathrm{m}$ sieve. The resulting phosphates washing waste (PWW) particles size are below $70 \mu \mathrm{m}$. The phosphate washing waste was calcined at $700^{\circ} \mathrm{C}$ and $900^{\circ} \mathrm{C} . n$ Both calcined and uncalcined waste were investigated with X-ray fluorescence (XRF), Xray powder diffraction (DRX), Fourier transform infrared (FTIR), simultaneous differential thermal and thermogravimetric analyses (DTA-TG) and particle size analysis. This waste was activated with sodium hydroxide $(\mathrm{NaOH})$ and sodium silicate in order to produce geopolymeric materials. The influence of replacing PWW by $15 \%$ of metakaolin was also study. The results show that the highest compressive strength is obtained with metakaolin. The results also showed that compressive strength decreased with the increase of $\mathrm{NaOH}$ concentration.

Keywords: Phosphate washing waste, sodium hydroxide, sodium silicate, geopolymer.
\end{abstract}

\section{Introduction}

Waste recycling is an important feature in the context of sustainable development and also important to the circular economy. The natural Gafsa phosphate is extracted by CPG (Gafsa Phosphate Company) from sedimentary deposits of marine origin, their geological origin dates from about 50 million years. The most used techniques by CPG to extract the phosphate are washing and flotation to eliminate mineral and organic impurities. Tunisia is an international pioneer in the field of natural phosphate and mineral fertilizers and it is the second country in the world to develop a large percentage of its production of phosphate (nearly $80 \%$ ). The treatment of phosphate ore consists in removing the

${ }^{*}$ R.Dabbebi sterile matrix like clay, quartz to increase the percentage of $\mathrm{P}_{2} \mathrm{O}_{5}$ which can reach $37 \%$. The ore was washed with a flocculent. Afterwards, it was sorted according to the particle size. The biggest particles exceeding $2 \mathrm{~mm}$ were stored in heaps and the finest particles with a dimension below $70 \mu \mathrm{m}$ are the phosphate washing waste. This product was placed in a basin with around a dozen hectares $[1,2]$. This waste is hazardous in nature constituting a potential source of pollution and its storage creates environmental problems related to land pollution. Fig 1 shows a view of the sludge pond.

According to Van Deventer et al. [3] geopolymers are further subsets of inorganic polymers, where the

rawiabali@gmail.com 
binding phase is almost exclusively aluminosilicate and very highly coordinated.

The available calcium content of the reacting components is usually low; to enable formation of a pseudo-zeolitic network structure rather than the chains characteristic of calcium silicate hydrates.

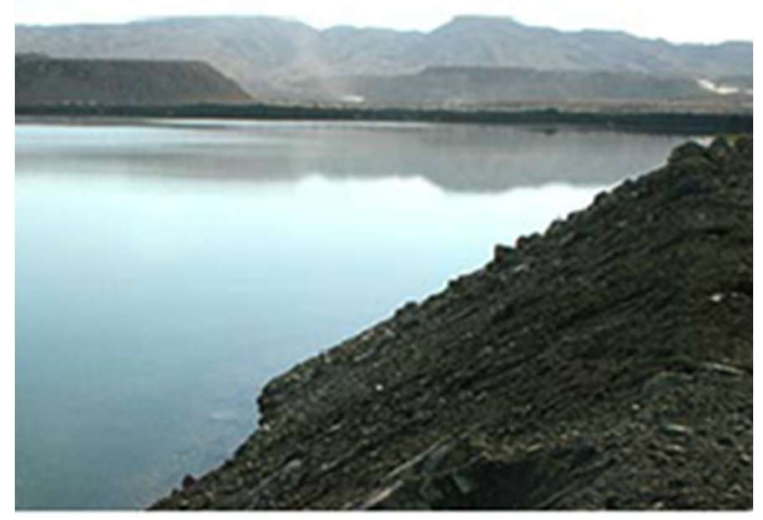

Fig 1.Tunisian phosphate sludge pond

Fig 2 shows the distinction between geopolymers and other binders. The activation of aluminosilicates can also be performed with an acid solution such as in the case of phosphate geopolymer or silico phosphate. Geopolymers have the ability to reuse several wastes $[4,5]$. They still present some shortcomings that need to be addressed such as a high cost and some durability problems [6]. Large number of researchers worked with a variety of raw materials to synthesis geopolymers. However, no work has addressed the use of phosphate washing waste as a raw material. Therefore, this study discloses preliminary results regarding not only the characterization of that raw material but also its geopolymerization.

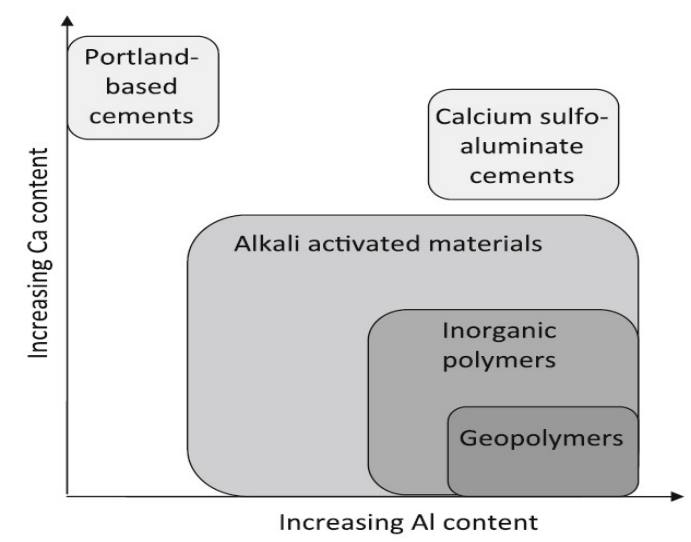

Fig 2.Classification of different subsets of alkali activated materials with comparisons to OPC and calcium sulfoaluminate binder chemistry

\section{Experimental works}

The phosphate washing waste used in this study was taken from Metlawi's storage ponds (laverie VI) a region in the south of Tunisia. The phosphate washing waste was slurry with or without flocculent. Particle size of the slurry with flocculant was characterized by laser diffraction (Fritsch analysette 22 micritec plus). Then, It was filtered and dried at $105^{\circ} \mathrm{C}$ for 24 hours to remove the water. The dried phosphate washing waste was crushed, and then sieved to $100 \mu \mathrm{m}$. It was calcined in a muffle furnace LAB TechDaihan LAB TECH CO.LTD for 2 hours with heating rate $5 \%$ min at $700^{\circ} \mathrm{C}$ and $900^{\circ} \mathrm{C}$. After calcination the samples were characterized with XRF, XRD and FTIR. The XRF were conducted by $\mathrm{X}$ ray fluorescence (Philips X'unique II), the X-ray diffraction (XRD) was conducted on a Bruker D8 Discover with $\mathrm{Cu}-\mathrm{K} \alpha$ radiation $(\lambda=1,54060 \AA)$ at $40 \mathrm{kV}$ and $40 \mathrm{~mA}$. Each sample was scanned from $5^{\circ}$ to $60^{\circ}$ at a speed of $0.02^{\circ} \mathrm{s}^{-}$ 1. The FTIR were scanned from 400 to $4000 \mathrm{~cm}^{-1}$ wavenumbers using the Fourier Transform infrared model perkin Elmer spectrum BX spectrometer. The thermal behaviour of the phosphate washing waste was performed under argon atmosphere with heating rate $10^{\circ} \mathrm{C} / \mathrm{min}$ from ambient to $1000^{\circ} \mathrm{C}$ with TA instruments SDT 2960 Simultaneous. The compressive strength of the consolidate material was evaluated with three cylindrical specimens with $35 \mathrm{~mm}$ in diameter and 70 $\mathrm{mm}$ in height. The compression tests were carried out using a LLOYD Instruments LR50K apparatus equipped with a $50 \mathrm{kN}$ sensor. The descent rate of the upper platen was set at $0.2 \mathrm{~mm} / \mathrm{min}$.

\section{Results and discussion}

The chemical analysis of phosphate washing waste calcined and uncalcined was done by XRF and the results of this analysis are reported in the table 1 . The table shows that the PWW has an important quantity of $\mathrm{SiO}_{2}, \mathrm{CaO}, \mathrm{Al}_{2} \mathrm{O}_{3}$ and $\mathrm{P}_{2} \mathrm{O}_{5}$. Figs 3 and 4 show the distribution of the particles size of the phosphate washing waste with and without flocculent. The Fig 5 shows some samples of phosphate washing waste powder before and after calcination. 
Table 1.Chemical composition (\%) of PWW according to calcination temperature

\begin{tabular}{|c|c|c|c|}
\hline Oxides & $25^{\circ} \mathrm{C}$ & $7^{\circ 00^{\circ}} \mathrm{C}$ & $900^{\circ} \mathrm{C}$ \\
\hline $\mathrm{SiO}_{2}$ & 42 & 44.3 & 42.7 \\
\hline $\mathrm{Al}_{2} \mathbf{O}_{3}$ & 9.77 & 10 & 9.45 \\
\hline $\mathrm{CaO}$ & 26.5 & 24.9 & 26.7 \\
\hline $\mathbf{P}_{2} \mathbf{O}_{5}$ & 10 & 8.49 & 8.75 \\
\hline $\mathrm{Na}_{2} \mathrm{O}$ & 1.12 & 1.64 & 1.50 \\
\hline $\mathbf{K}_{2} \mathbf{O}$ & 0.673 & 0.798 & 0.779 \\
\hline MgO & 3.09 & 2.75 & 2.91 \\
\hline $\mathrm{SO}_{3}$ & 3.39 & 3.96 & 4.10 \\
\hline $\mathrm{Fe}_{2} \mathrm{O}_{3}$ & 2.31 & 2.32 & 2.39 \\
\hline LOI & 18 & 14.7 & 17 \\
\hline
\end{tabular}

PS: Phosphate sludge

Moisture of uncalcined PS $=0.1851 \%$

Melting temperature of $\mathrm{PWW} \mathrm{Tf}{ }^{\circ} \mathrm{C}=1150^{\circ} \mathrm{C}$

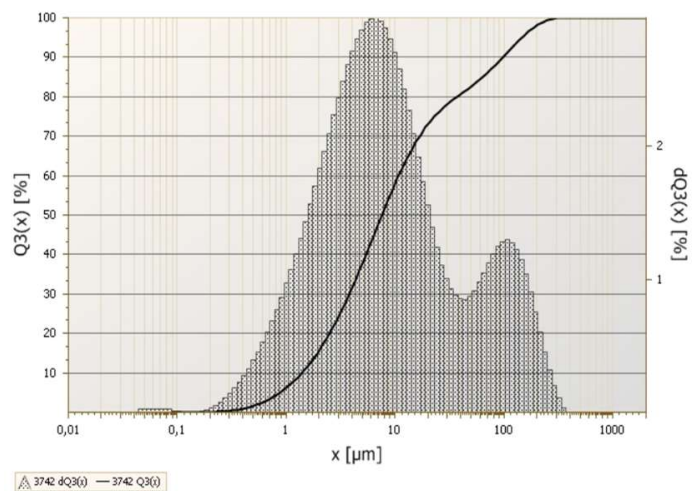

Fig 3. Particle size analysis of phosphate washing waste with flocculent

With flocculent the distribution is bimodal. The most dominant is between 0.9 and $60 \mu \mathrm{m}$, and the majority of particles have a diameter of $7.5 \mu \mathrm{m}$. The less dominant population is between 60 and $250 \mu \mathrm{m}$, with particles majority having an approximate diameter of $100 \mu \mathrm{m}$. The difference of the size particles can be explained by the presence of the flocculent used by the company to recover the maximum of water. Fig.4 shows the distribution of particles size of the phosphate washing waste without flocculent.

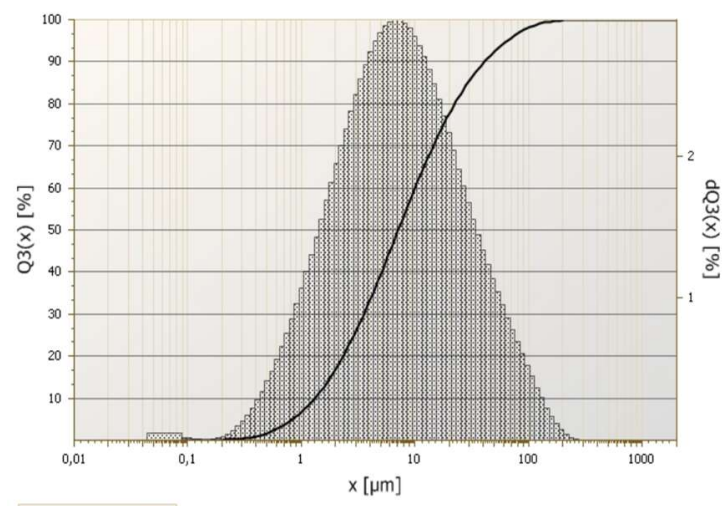

Fig 4. Particle size analysis of phosphate washing waste without flocculent



Fig 5. Phosphate washing waste powder before and after calcinations

The patterns of the XDR show the presence of amorphous and crystalline phases (Fig. 6).

$\mathrm{The} \mathrm{Ca} / \mathrm{P}$ ratio determined by the chemical composition of uncalcined material is $2.65>1.67$ : this indicates the presence of calcite or dolomite, or that there is a substitution of $\mathrm{PO}_{4}$ by $\mathrm{CO}_{3}$ [7], and this was confirmed by the XRD. The diffractogram shows the presence of calcite, fluorapatite, palygorskite, heulandites, quartz and gypsum. 


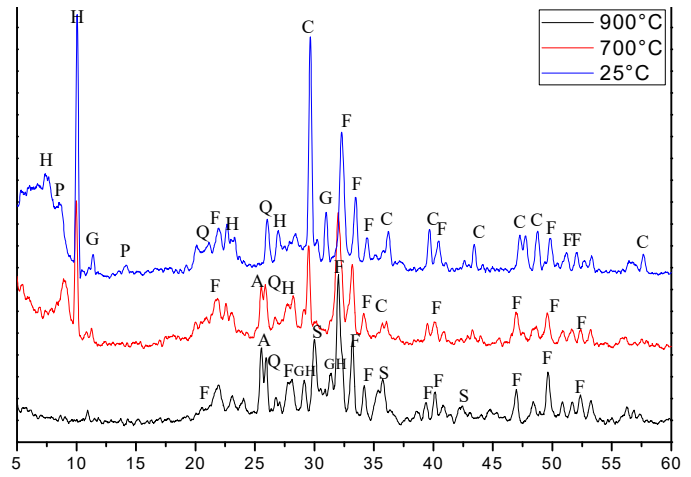

Fig 6. X ray diffractograms of the phosphate sludge uncalcined and calcined at $700^{\circ} \mathrm{C}$ and $900^{\circ} \mathrm{C}$. C: Calcite (PDF: 00-002-0629), H: Heulandites (PDF\#01-076-2214), G: Gypsum (PDF\#:00-021-0816) , Q: Quartz (PDF\#:01-070-2535), F: Fluorapatite (PDF\#:00-002-

0845), P: Palygorskite (PDF\#00-029-0855), A: Anhydrite (PDF\#:00-003-0368 ), S: Calcium Iron Silicate (PDF\#:00-003-

1134), GH: Gehlenite (PDF\#: 00-001-0982)

After calcination at $700^{\circ} \mathrm{C}$, the curve shows the disappearance of palygorskite, and the presence of a new phase anhydrite $\mathrm{CaSO}_{4}$ a decrease in the intensity of the peaks of heulandites and of calcite, this was supported by the FTIR. At $900^{\circ} \mathrm{C}$ the curve shows a total disappearance of heulandites and calcite and the appearance of new phase calcium iron silicate and gehlenite.

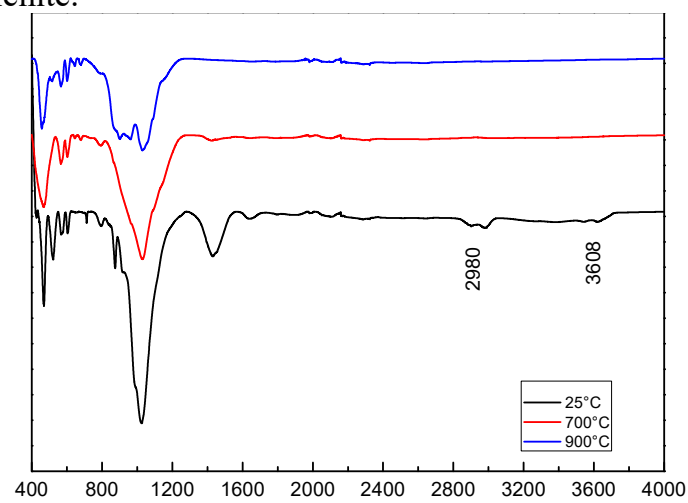

(a)

The fig. 7 shows the FTIR spectra of phosphate washing waste. The examination of the spectral shows bands at $1636-3543 \mathrm{~cm}-1$ confirming the presence of the stretching hydroxyl group $\left(\mathrm{OH}^{-}\right)$and these bands disappeared at $700^{\circ} \mathrm{C}$ and $900^{\circ} \mathrm{C}$. The peak at $3616 \mathrm{~cm}^{-}$ ${ }^{1}$ which characterizes the $\mathrm{OH}$ stretching vibration of the palygorskite mineral confirms the results present in the XRD patterns. The organic matter was shown by the presence of band at $2980 \mathrm{~cm}^{-1}$ and it disappeared also at $700^{\circ} \mathrm{C}$ and $900^{\circ} \mathrm{C}$.

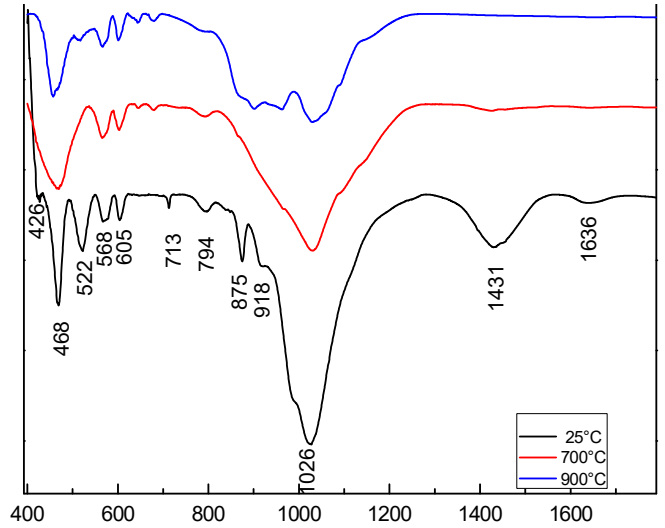

(b)

Fig 7. FTIR spectra of phosphate washing waste

(a) $400-4000 \mathrm{~cm}^{-1}$; (b) $400-1600 \mathrm{~cm}^{-1}$ )

The bands at 713,875 and $1431 \mathrm{~cm}^{-1}$ confirmed the presence of carbonate $\mathrm{CO}_{3}{ }^{2-}$ [8]. These 3 bands were vanished at $900^{\circ} \mathrm{C}$ and the weight loss was attributed to the decomposition of carbonates. Asymmetric stretch silicate bands were observed at $1025 \mathrm{~cm}^{-1}$, a deformation band of Si-O-Al at $522 \mathrm{~cm}^{-1}$, a trace of quartz at $794 \mathrm{~cm}^{-1}$ and a deformation band at $426 \mathrm{~cm}^{-1}$ of Si-O. Two bands at 468 and 568 correspond to $\mathrm{PO}_{4}{ }^{3-}$ . The FTIR spectrum shows also a deformation band at $918 \mathrm{~cm}^{-1}$ of Al-OH-Al [9] of the palygorskite.

Fig. 8 shows the thermal behavior of phosphate washing waste, the first mass loss is an endothermic effect around $100^{\circ} \mathrm{C}$ corresponds to the removal of adsorbed water (moisture). The second mass loss is between $200-550^{\circ} \mathrm{C}$, an endothermic peak corresponding to structural water of the natural zeolite [10], and an exothermic peak corresponding to the combustion organic matter. The third mass loss is an endothermic peak reflecting the decomposition of carbonates calcite $\mathrm{CaCO}_{3}$ with release of $\mathrm{CO}_{2}$.

Mixtures with phosphate washing waste (uncalcined and calcined at $700^{\circ} \mathrm{C}$ and $900^{\circ} \mathrm{C}$ ) activated with sodium silicate and sodium hydroxide were tested.

The chemical composition of the sodium silicate solution by mass was $\mathrm{Na}_{2} \mathrm{O}: 10.6 \%, \mathrm{SiO}_{2}: 26.5 \%$ and water: $45 \%$ with bulk density $1390 \mathrm{~kg} / \mathrm{m} 3$. The sodium hydroxide solution was obtained by dissolving different amount of sodium hydroxide pellets (98\% purity) in distilled water to have different concentrations 7, 9, 10, 12 and $14 \mathrm{M}$ before 24 hours of the mixing. 


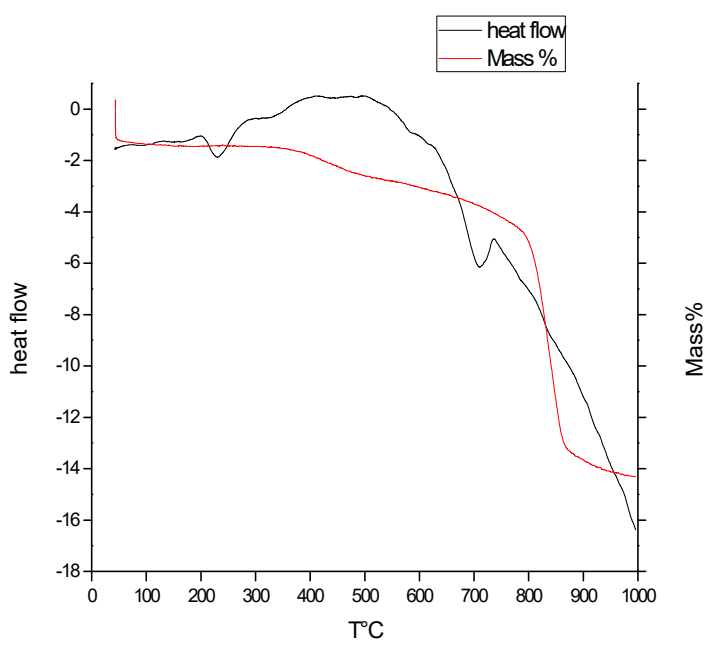

Fig 8 . Thermal behavior of phosphate washing waste

concentrations $7,9,10,12$ and $14 \mathrm{M}$ before 24 hours of the mixing. The liquid/solid ratio of the mixture was $\sim 0.75$. The obtained mixtures were placed in a closed polystyrene mold and compacted with vibrating table to remove entrapped air bubbles. After they were cured at room temperature for 7 days. A summary of the different mixtures is presented in table 2 .

Table 2. Summary of the mixtures

\begin{tabular}{|l|l|l|l|l|}
\hline Liquid/solid & N. & $\begin{array}{l}\text { C.P.S } \\
900^{\circ} \mathrm{C}\end{array}$ & $\begin{array}{l}\text { C.P.S } \\
700^{\circ} \mathrm{C}\end{array}$ & $\begin{array}{l}\text { C.P.S } \\
700^{\circ} \mathrm{C}+\mathrm{MK}\end{array}$ \\
\hline $\begin{array}{l}\text { C.H } \\
7,9,10,12,14 \mathrm{M}\end{array}$ & NO & NO & NO & NO \\
\hline S.S & NO & NO & YES & YES \\
\hline S.H in S.S & NO & NO & NO & NO \\
\hline S.S+7M & NO & NO & YES & YES \\
\hline S.S+9M & NO & NO & YES & YES \\
\hline S.S+10M & NO & NO & YES & YES \\
\hline S.S+12M & NO $+14 \mathrm{M}$ & NO & YES & YES \\
\hline N.P. & NO & YES & YES \\
\hline
\end{tabular}

N.C.P: uncalcined phosphate sludge

C.P.S: calcined phosphate sludge
Consolidate material "yes" refers to a solid state after 24 hours while non-consolidate material refers to mixtures that were still fresh after 24 hours. This are labelled NO in the table 2. S.H refers to $\mathrm{NaOH}$ solution. $\mathrm{S} . \mathrm{S}+\mathrm{xM}$ refers to sodium silicate solution with sodium hydroxide solution. Those mixtures were composed by $50 \%$ of sodium silicate solution and $50 \%$ of sodium hydroxide solution. S.H in S.S refers that the pellets of sodium hydroxide were dissolved in the sodium silicate solution. The uncalcined powder and calcined at $900^{\circ} \mathrm{C}$ show different results compared with powders calcined at $700^{\circ} \mathrm{C}$ which implies that the two powders have more stable phases.

Fig. 9 shows the compressive strength results for mixtures with 7 curing days with sodium silicate and sodium hydroxide. The maximum strength $(6 \mathrm{MPa})$ was obtained when using a sodium hydroxide concentration below 10M. Mixtures show lower compressive strength for higher sodium hydroxide concentration. Mixtures with $15 \%$ metakaolin showed a higher compressive strength with a maximum of $10 \mathrm{MPa}$ for a sodium hydroxide concentration of $7 \mathrm{M}$.

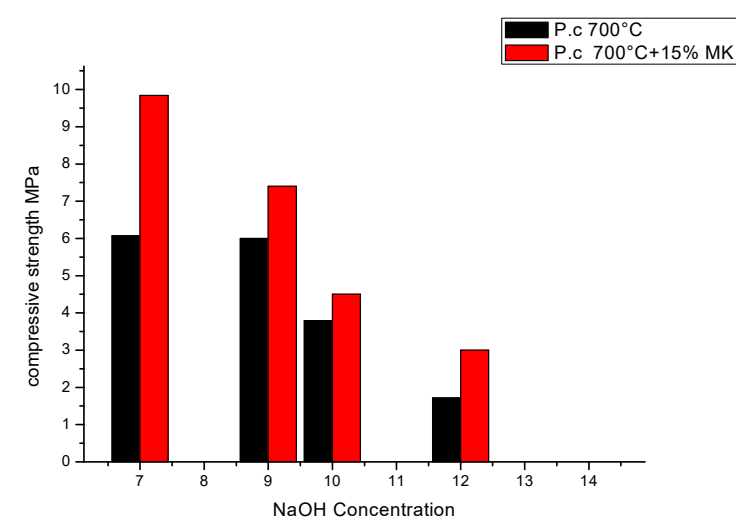

Fig 9. Compressive strength of the geopolymer with sodium silicate and different $\mathrm{NaOH}$ concentration

The concentration of sodium hydroxide affects the microstructure and the compressive strength of geopolymers [11]. The increase of $\mathrm{NaOH}$ concentration in the aqueous phase of geopolymeric system decreases the dissolution rate of $\mathrm{Si}$ and $\mathrm{Si}-\mathrm{Al}$ phase of phosphate washing waste calcined at $700^{\circ} \mathrm{C}$, which affects negatively the mechanical properties of the obtained materials. An excess of hydroxide ion $\mathrm{OH}^{-}$ concentration caused a precipitation of aluminosilicate gel at a very early stages, and it will accelerate the dissolution, so the geopolymerisation will be stopped which leads to a lower compressive strength [12]. 
Moreover, in the condition of high $\mathrm{NaOH}$ concentration, the sodium cation consumes the surfaces species (T-OH and T-O-), so the chemical bonding between the insoluble solid particles and geopolymeric framework take place in the final stage of the geopolymerization [13].

Fig 10 shows the compressive strength results for mixtures with 7 curing days with only sodium silicate as activator.

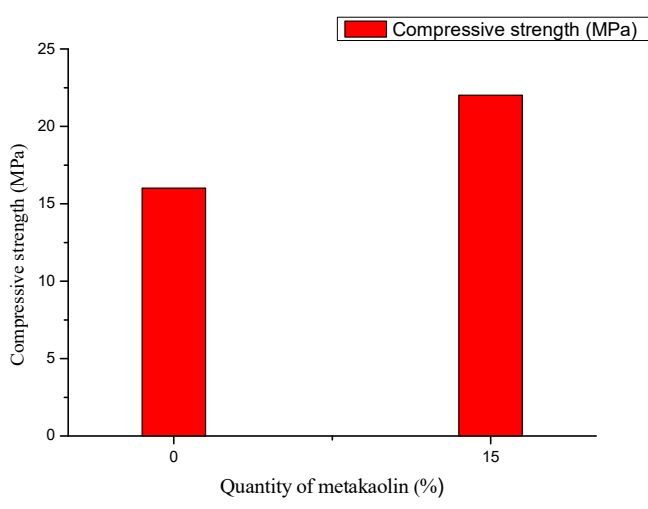

Fig 10. Compressive strength of the geopolymer with only sodium silicate

From the fig 10, the compressive strength of the samples activated with only sodium silicate solution S.S was equal to $16 \mathrm{MPa}$ for the PS. This mixed with $15 \%$ of metakaolin shows a compressive equal to 22 $\mathrm{MPa}$. These results were higher compared to the results mentioned in fig 9. The results show that the compressive strength depends necessarily on the type of the alkali activators. The results can be explained by the presence of more active silica provided by the sodium silicate which involve in the geopolymerization process and it improves the compressive strength [14]. these types of mixtures were avoided because of the high cost of the sodium silicate [15]

\section{Conclusions}

In this research, the Tunisian phosphate washing waste was studied by fluorescence X, X-ray diffraction, FTIR, thermal and particle size analysis. The structural changes of phosphate washing waste after calcinations at 700 and $900^{\circ} \mathrm{C}$ were studied by fluorescence and $\mathrm{X}$ ray diffraction and FTIR. After the calcination, physical and chemical properties of the phosphate washing waste are affected, and the preliminary tests of geopolymerization confirmed the results. The phosphate sludge can be used as a source material for making geopolymers cured at ambient temperature.
The geopolymer pastes and the compressive strength are dependent on the structure of the precursor and on the $\mathrm{NaOH}$ concentration. The sodium hydroxide concentration of $7 \mathrm{M}$ with sodium silicate and $15 \%$ of metakaolin shows the higher compressive strength after cured 7 days. The results also show that an increase of sodium hydroxide concentration decrease the compressive strength. We should mention also that the compressive strength of geopolymers based on phosphate washing waste and sodium silicate without and with $15 \%$ of metakaolin show the higher compressive strength after 7 days of curing: $16 \mathrm{MPa}$ and $22 \mathrm{MPa}$.

\section{Acknowledgment}

The authors acknowledge the Gafsa Phosphate Company "CPG Tunisia" for providing us the phosphate washing waste sample and the Portuguese Foundation for Science and Technology (FCT) for the finance of the project UID/ECI/04047/2013.

\section{References}

[1] Khaled Boughzela, N. F., Khaled Bouzouita, Habib Ben Hassine: Etude minéralogique et chimique du phosphate naturel d'Oum El Khecheb (Gafsa, Tunisie); Revue science des matériaux, 2015; Vol. 6. pp. 11-29. [2] Loutou, M.; Hajjaji, M.; Mansori, M.; Favotto, C.; Hakkou, R. Phosphate sludge: Thermal transformation and use as lightweight aggregate material. Journal of Environmental Management 2013, 130, 354-360.

[3] Van Deventer, J.; Provis, J.; Duxson, P.; Brice, D.: Chemical Research and Climate Change as Drivers in the Commercial Adoption of Alkali Activated Materials. Waste Biomass , $2010 ; 1: 145-155$

[4] Bernal, S.; Rodríguez, E.; Kirchheim, A.; Provis, J.: Management and valorisation of wastes through use in producing alkali-activated. Journal of Chemical Technology \& Biotechnology (in press) 2016

[5] Payá, J.; Monzó, J.; Borrachero, M.; M. Tashima, M.: Reuse of aluminosilicate industrial waste materials in the production of alkali-activated concrete binders, in Handbook of Alkali-Activated Cements, Mortars and Concretes, F. Pacheco-Torgal, J. Labrincha, A. Palomo, C. Leonelli, P. Chindaprasirt, Eds, WoodHead Publishing, Cambridge, 2014; pp. 487-518

[6] Pacheco-Torgal, F.; Abdollahnejad, Z.; Miraldo, S.;Kheradmand,M. Alkali-activated cement-based binders (AACB) as durable and cost competitive low $\mathrm{CO} 2$ binders: Some shortcomings that need to be addressed, in Handbook of low carbon concrete, $1^{\text {st }}$ A. 
Nazari, J. Sanjayan, , Elsevier Science and Tech, Waltham, 2016; pp.195-216.

[7] Slansky, M.: Geology of sedimentary phosphates; Elsevier Science Pub. Co. Inc.,New York, NY; None, 1986.

[8] Huang, C. K., and Paul F. Kerr. " Infrared study of the carbonate minerals." American Mineralogist 45.3-4 (1960): 311-324

[9] Neji, S. B.; Trabelsi, M.; Frikha, M. H. Activation d'une argile smectite Tunisienne à l'acide sulfurique: rôle catalytique de l'acide adsorbé par l'argile. Journal de la Société Chimique de Tunisie 2009, 11, 191-203.

[10] Gelves, J.; Gallego, G. S.; Marquez, M. Mineralogical characterization of zeolites present on basaltic rocks from Combia geological formation, La Pintada (Colombia). Microporous and Mesoporous Materials 2016, 235, 9-19.

[11] Somna, K.; Jaturapitakkul, C.; Kajitvichyanukul, P.; Chindaprasirt, P. NaOH-activated ground fly ash geopolymer cured at ambient temperature. Fuel 2011, 90, 2118-2124.

[12] Lee, W.; Van Deventer, J. The effects of inorganic salt contamination on the strength and durability of geopolymers. Colloids and Surfaces A: Physicochemical and Engineering Aspects 2002, 211, 115-126.

[13] Panias, D.; Giannopoulou, I. P.; Perraki, T. Effect of synthesis parameters on the mechanical properties of fly ash-based geopolymers. Colloids and Surfaces A: Physicochemical and Engineering Aspects 2007, 301, 246-254.
[14]T. Phoo-ngernkham, S. Hanjitsuwan, N. Damrongwiriyanupap, and P. Chindaprasirt, "Effect of sodium hydroxide and sodium silicate solutions on strengths of alkali activated high calcium fly ash containing Portland cement," KSCE Journal of Civil Engineering, vol. 21, pp. 2202-2210, 2016.

[15]Z. Abdollahnejad, F. Pacheco-Torgal, T. Félix, W. Tahri, and J. Barroso Aguiar, "Mix design, properties and cost analysis of fly ash-based geopolymer foam," Construction and Building Materials, vol. 80, pp. 18 30, 2015. 